on trial for a specified term, or if once adopted is it permanently binding? 6. In a town of 20,000 inhabitants, a public meeting has been convened by requisition by the mayor, and been presided over by him under the advice of the town clerk. A resolution has been passed that no fever hospital shall be erected or maintained. What course is open to the Corporation, as sanitary authority, in reference to the Notification Act? 7. If a shopkeeper is ruined by the publication of the fact of his having fever in his house by the visits of the medical officer of health, is the sanitary authority liable for damages through voluntarily adopting the Act?

Your kind consideration of the above questions will greatly oblige, Your obedient servant,

November, 1889

VERITAS.

* * 1. A medical officer of health has no legal right of entry into private premises merely because he believes or knows that infectious disease prevails there; but he can acquire the legal right under Section 102 of the Public Health Act, 1875, if he has reason to believe in the existence on the premises of a nuisance such as is contemplated under Section 91 of that Act. But, as a matter of actual practice, a medical officer of health is rarely refused entrance to premises. We may add that he has no right whatever to examine the sick; but he is often allowed to do so in conference with the medical practitioner in attendance. 2. The terms of Section 102, already referred to, coupled with the provisions of Section 120 of the same Act, show that it is not so much the directions of the medical officer of health as those which, on his advice, the sanitary authority or the justices require to be carried out, which must be followed. 3. Our answer, speaking generally, would certainly be-No. But we can conceive circumstances in which the duty of a medical officer of health towards the public and his authority might justify him in demanding further measures of disinfection than have already been taken. Such occurrences are, however, rare in the extreme. 4. We imagine that a claim would lie in the case of wilful and unnecessary damage. 5. We gather from the fact that revocation and variation of an Order under the Infectious Disease (Notification) Act, 1889, is limited to extensionsin the definition of the term "infectious disease," that no such revocation is contemplated as regards the adoption of the Act generally. But the point is not specifically mentioned in the Act. 6. There is no compulsory power as to the erection of a hospital for infectious diseases either under the Public Health Act or the Infectious Disease (Notification) Act. The responsibility for the consequences of not taking action in this matter under Section 131 of the Public Health Act, 1875, must in such a case lie with the authority. 7. We cannot conceive that any liability for damages can lie against any authority "through voluntarily adopting" an Act the voluntary adoption of which has been approved by Parliament. -ED. L.

\section{HOSPITAL OUT-PATIENT REFORM.}

To the Editors of THE LANCET.

SiRs, - In reply to Dr. Harris, I wish to say that, for my part, I should be glad to accept his suggestion that, instead of having a "wage limit" of $20 \mathrm{~s}$. for single and $25 \mathrm{~s}$. for married wage earners, we reduce this to $15 s$. and $21 s$, and $2 s$. for each child-that is, supposing there be a man and wife and eight children, this man, wife, and family, although making up to $37 s$. per week, would all be eligible for out-door medical aid.

If men with such practical experience as Dr. T. Harris help in solving our difficulties our work will be rendered light. There are some hospital doctors who say to me, "We do not care about abuse, as we only wish to get a hold of the interesting cases." Such may rest assured that when the plan of "wage limits" and inspection come into force the interesting cases will not be taken from them, as such will always be eligible for treatment in the wards. I am sorry to see that petty trade jealousies tend to mar some of ou discussions. Let me assure those men who keep "sixpenny dispensaries" and unqualified assistants that the proposed hospital reforms will not injure them.

Mr. Nelson Hardy, I trust, will understand that in the matter of details I am very anxious to agree to any practical changes in the proposed tariff of fees. I do not advocate any alliance with chemists, but merely have said that we might follow the plan pursued by hospitals and doctors holding club appointments. The former frequently contract with chemists for the supply of drugs all the year round, taking the price-list of a certain month, this price to remain good for twelve months. Doctors often contract with the chemist to dispense each prescription at $4 \frac{1}{2} d$. If we do not secure the aid of the chemists, they will only enter into fierce competition with us, and will have a number of doctors in their back parlours to prescribe for patients. If anyone supposes that the system of "free rnedical aid" is to be extended to the entire community, after the plan of the Poor-law Service, thereby throwing greater taxation on the already overtaxed middle classes, then I think such a millennium is very far off. Doctors have now been ascitating for the last forty years for a reform of our medical charities. Is it not, therefore, time we adopted those practical efforts as made in Manchester, and ceased pursuing visionary proposals?

I am, Sirs, yours faithfully,

Liverpool, November, $1889 . \quad$ ROBERT R. RENTOUL.

\section{DR. RENTOUL'S SCHEME: THE GENERAL PRACTITIONERS HOAXED. \\ To the Editors of THE LANCET.}

SIRs,-A special meeting of the Metropolitan Branch of the British Medical Association was held in the board-room of Bethlem Hospital on the 13th inst., for the professed purpose of obtaining the opinion of the profession in Soutb London upon the so-called "scheme of Dr. Rentoul," and an invitation was given to all practitioners to attend it. The meeting was tolerably large, and, from what I could observe of it, the non-members of the Association outnumbered the members. Mr. John Page Hentsch rose to move the following resolution: "That this meeting con. siders Dr. Rentoul's scheme impracticable, and that even if it were practicable it would be disadvantageous to the great bulk of the general practitioners"; but the chairman ruled that he could not put it, for the reason that he was not member of the Association. Hereupon Mr. Campbell Boyd, a member, moved the resolution for Mr. Hentsch, and it was seconded by Mr. Oldfield, another member. When the resolution was put to the meeting it was ruled by the chairman that non-members could not vote; nevertheless, the members of the Association carried it with applause, and by a majority of nearly three to one. Non-members, as 1 have stated, were not allowed to move resolutions nor to record their opinion by voting. Therefore I say they were simply hoaxed by the invitation they received. But such are the ways of the officials of the British Medical Associa tion, and I for one am in no way surprised.

Nov. 25th, 1889 I am, Sirs, faithfully yours,

\section{THE DETECTION OF COLOUR-BLINDNESS. To the Editors of THE LANCET.}

SIRS,-Since the publication of my letter in THE LANCET, an example of the practical worthlessness of Holmgren's test has come to my knowledge. Mr. Clement Stretton informs me that when members of the Associated Society of Locomotive Engineers and Firemen fail in this test, the are privately instructed by girls in wool shops, and then pass with ease. Those who support Holmgren's method may doubt whether these were true cases of colour-blindness. I am inclined to think that they were. At any rate it is possible to instruct a red-green colour-blind so as to enable him to pass through Holmgren's test with ease. I have taught an uneducated red-green colour-blind (of course not an applicant for railway employment) to pass through Holmgren's test with less than five minutes' instruction. He picked out the correct colours with ease and certainty. Previously he had picked out the ordinary confusion colours. Holmgren has been the chief advocate for the method of matching colours as against that of naming them. But the method of matching colours should, to be properly carried out, be one of mentally 